\title{
A Narrative Review of Implementing Precision Oncology in Metastatic Castration-Resistant Prostate Cancer in Emerging Countries
}

\author{
Shouki Bazarbashi · Wen-Pin Su • Siew W. Wong • Ramanujam A. Singarachari • \\ Sudhir Rawal · Maria I. Volkova · Diogo A. Bastos
}

Received: May 14, 2021 / Accepted: June 14, 2021 / Published online: July 8, 2021

(C) The Author(s) 2021

\section{ABSTRACT}

The therapeutic landscape of metastatic castration-resistant prostate cancer (mCRPC) has evolved considerably with the introduction of newer agents, such as poly-ADP ribose polymerase (PARP) inhibitors targeting DNA damage repair mutations. Combining and sequencing novel and existing therapies appropriately is necessary for optimizing the management of mCRPC and ensuring better treatment outcomes. The purpose of this review is to provide evidence-based answers to key clinical questions on treatment selection, treatment

\section{S. Bazarbashi $(\square)$}

Oncology, King Faisal Specialist Hospital and

Research Center, Alzahrawi Street, Riyadh 11211,

Saudi Arabia

e-mail: bazarbashi@gmail.com

W.-P. Su

Institute of Clinical Medicine, College of Medicine,

National Cheng Kung University, No. 35, Rd.

Xiao-Tong, Tainan, Taiwan

W.-P. Su

Departments of Oncology and Internal Medicine, National Cheng Kung University Hospital, College of Medicine, National Cheng Kung University, No. 35, Rd. Xiao-Tong, Tainan, Taiwan

S. W. Wong

Medical Oncology, The Cancer Centre, Orchard

Road, Singapore 238859, Singapore sequencing patterns, and factors influencing treatment decisions in the management of mCRPC in the era of PARP inhibitors. This article can also serve as a comprehensive guide to clinicians for optimizing genetic testing and counseling and management of patients with mCRPC. Although the PROfound study has validated the concept of PARP sensitivity across multiple genes associated with homologous recombination repair (HRR) in $\mathrm{MCRPC}$ and highlighted the importance of genomic testing in this at-risk patient population, it still remains unclear how patients with rarer HRR mutations will respond to PARP inhibitors. Therefore, realworld data obtained through registry-based randomized controlled trials in the future may

\section{R. A. Singarachari}

Division of Oncology and Hematology, Department of Internal Medicine, Sheikh Khalifa Medical City, Karamah Street, Abu Dhabi, UAE

S. Rawal

Uro-Oncology, Rajev Gandhi Cancer Institute \& Research Centre, Rohini, New Delhi, India

M. I. Volkova

Oncourology, N.N. Blokhin Cancer Center, Kashirskoye shosse, 24, Moscow 115478, Russia

D. A. Bastos

Oncology, Hospital Sirio-Libanês, 91 Adma Jafet street, São Paulo, Brazil 
help produce robust scientific evidence for supporting optimal clinician decision-making in the management of mCRPC.

Keywords: Castration-resistant; Genetic testing; Metastasis; PARP inhibitors; PROfound study; Prostate cancer

\section{Key Summary Points}

Metastatic castration-resistant prostate cancer (mCRPC) is a global health issue with a poor prognosis.

Putative predictive biomarkers, such as homologous recombination repair (HRR) mutations, would benefit the treatment.

Poly-ADP ribose polymerase (PARP) inhibitors represent a promising treatment opportunity in patients with mCRPC harboring HRR mutations.

Genomic and proteomic profiling and liquid tumor profiling will play a vital role in predicting therapeutic efficiency in patients with mCRPC with rarer mutations.

Access to real-world data would benefit clinicians and researchers in terms of increasing understanding of the rarer genes and optimizing both treatment selection and treatment sequencing patterns in mCRPC.

\section{DIGITAL FEATURES}

This article is published with digital features, including a summary slide, to facilitate understanding of the article. To view digital features for this article go to https://doi.org/10.6084/ m9.figshare.14779668.

\section{INTRODUCTION}

Prostate cancer was the fourth most commonly diagnosed cancer in 2020, with an estimated $1,414,259$ new cases $(7.3 \%$ of all new cancer cases) and 375,300 deaths (3.8\% of all deaths due to cancer) worldwide [1]. With respect to the male population, it was the second most commonly diagnosed cancer (14.1\%) and the fifth leading cause of cancer deaths (6.8\%) worldwide in 2020 [1]. The treatment options for early-stage (localized) prostate cancer, including watchful waiting/active surveillance, radical prostatectomy, and external beam radiation therapy, are usually curative. However, about $30-70 \%$ of patients diagnosed with localized disease eventually develop metastases within 10 years of the initial diagnosis [2]. Testosterone suppression using novel androgen receptor (AR)-targeted (ART) therapies is the mainstay of initial treatment for patients with metastatic hormone-sensitive prostate cancer. It involves the use of luteinizing hormone-release hormone (LHRH) agonists/antagonists (chemical castration) or orchiectomy (surgical castration). While most of these patients achieve a substantial decline in the prostate-specific antigen (PSA) levels, 10-20\% develop metastatic castration-resistant prostate cancer (mCRPC) within 5 years of diagnosis, with the median survival ranging from 15 to 36 months [3].

Over the past 10 years, the therapeutic landscape of mCRPC has evolved considerably with the introduction of newer agents, such as docetaxel, cabazitaxel, abiraterone, enzalutamide, apalutamide, and darolutamide, and, more recently, poly-ADP ribose polymerase (PARP) inhibitors, such as olaparib, niraparib, and talazoparib. In this scenario, optimizing treatment sequencing is a daunting task for the clinicians. Hence, the purpose of this review is to: (1) describe the current treatment landscape of mCRPC and the recent advances in mCRPC treatment using precision oncology; (2) highlight recommendations for adopting treatment strategies based on precision oncology in emerging markets; and (3) provide suggestions on addressing the key knowledge gaps in the treatment of mCRPC. 
This article is based on previously conducted studies and does not contain any new studies with human participants or animals performed by any of the authors.

\section{CURRENT TREATMENT LANDSCAPE FOR MCRPC}

Systemic treatment is the mainstay of therapy for mCRPC. Over the past 10-15 years, multiple therapeutic agents have been tested in trials and proven to provide clinically meaningful benefits in MCRPC, and subsequently approved by the
US Food and Drug Administration (US FDA; Table 1).

\section{Management of mCRPC Prior to the Evolution of Precision Oncology: Key Clinical Trials, Timelines, and Sequencing Trends}

\section{Chemotherapy}

Mitoxantrone, the first cytotoxic chemotherapy, was approved for mCRPC based on improved palliative responses in pain-related measures [4] but showed no survival benefit [5].

Table 1 Approved therapies for the treatment of metastatic castration-resistant prostate cancer

Drug Treatment target

References (first author; of key studies that led to approval)

Chemotherapy

$\begin{array}{lll}\text { Docetaxel } & \text { Microtubules } & \text { Petrylack [7] } \\ \text { Cabazitaxel } & \text { Microtubules } & \text { De Bono [8] }\end{array}$

Novel androgen receptor-targeted therapies

\begin{tabular}{lll}
$\begin{array}{l}\text { Abiraterone } \\
\text { Enzalutamide }\end{array}$ & CYP17A1 & De Bono [11] \\
$\begin{array}{l}\text { Immunotherapy } \\
\text { Sipuleucel-T }\end{array}$ & AR & Beer [14] \\
Ex-vivo activation of PBMCs & via GM-CSF and PAP & Kantoff [18] \\
Pembrolizumab & PD-1 & Antonarakis [72] \\
$\begin{array}{l}\text { Bone-targeting agents } \\
\text { Radium 223 }\end{array}$ & Bone & \\
$\begin{array}{l}\text { Denosumab } \\
\text { Zoledronic acid }\end{array}$ & $\begin{array}{l}\text { RANKL } \\
\text { PARP inhibitors }\end{array}$ & Parker [19] \\
Rucaparib & Small molecule inhibitor of PARP1, & Liede [21] \\
Olaparib & PARP2, and PARP3 & Liede [21] \\
\hline
\end{tabular}

$A R$ Androgen receptor, $C Y P$ cytochrome $\mathrm{P} 450, G M-C S F$ granulocyte-macrophage colony-stimulating factor, $P A P$ prostatic acid phosphatase, $P A R P$ Poly (ADP-ribose) polymerase, $P B M C s$ peripheral blood mononuclear cells, $P D-1$ programmed cell death-1, RANKL Receptor activator of nuclear factor kappa-B ligand 
In 2004, docetaxel was the first systemic chemotherapy to demonstrate survival benefit in mCRPC. Docetaxel was studied in two prospective phase III trials: the TAX 327 trial [6] and the Southwest Oncology Group (SWOG) trial [7]. In both studies, docetaxel prolonged median overall survival (OS) by 1.9-2.4 months, thereby establishing docetaxel as the standard of care for mCRPC in 2004 [6, 7]. Cabazitaxel, another taxane, has demonstrated activity in docetaxel-resistant prostate cancers. It was approved by the FDA in 2010 based on the results of the TROPIC trial, in which patients receiving the combination cabazitaxel/prednisone had significantly longer progression-free survival (PFS) and OS than those receiving the combination mitoxantrone/prednisone (PFS: 2.8 vs. 1.4 months; OS: 15.1 vs. 12.7 months, respectively) [8].

\section{Novel Androgen Receptor Targeted Therapies}

Androgen receptor-regulating genes presumably participate in various cellular processes that contribute to the initiation and progression of prostate cancer [9]. Until 2004, patients with mCRPC who progressed on novel ART therapies were treated with additional secondary hormonal agents, including antiandrogens such as bicalutamide and nilutamide [10]. Between 2011 and 2012, abiraterone, a new androgen biosynthesis inhibitor, and enzalutamide, an AR blocker with a higher affinity to AR, were approved as the first- and second-line therapies for mCRPC, respectively.

The approval of abiraterone was based on a multi-national phase III trial, COU-AA-301, in which the combination abiraterone/prednisone (1000 mg) improved the OS compared to placebo (14.8 vs. 10.9 months, respectively) in patients with mCRPC who had progressed with prior ART therapy and docetaxel [11]. Furthermore, the phase III COU-AA-302 trial conducted in mCRPC patients who showed progression when on ART therapy, but had no prior treatment with docetaxel, demonstrated superior OS (34.7 vs. 30.3 months) and median radiographic PFS (16.5 vs. 8.3 months) in the abiraterone group (1000 $\mathrm{mg}$ ) as compared to the placebo group [12, 13].
The clinical efficacy of enzalutamide has been established in two phase III trials: PREVAIL [14] and AFFIRM [15]. It is also evident that enzalutamide is a treatment option for mCRPC patients in both the pre- and post-docetaxel settings and represents a reasonable choice for men who are not candidates for chemotherapy [16]. In 2017, another AR blocker, apalutamide, was successfully evaluated in a phase II study in patients with progressive mCRPC with and without prior chemotherapy with the combination abiraterone + prednisone (AAP); the PSA response rate after 12 weeks for AAP-naïve patients and patients who were treated with AAP previously was 88 and $22 \%$, respectively, [17].

\section{Immunotherapy}

Sipuleucel-T is the first and only immunotherapy to be approved by the FDA in 2010 for the treatment of mCRPC. An independent phase III study (D9902B; the IMPACT [Immunotherapy for Prostate Adenocarcinoma Treatment) trial]) revealed that the use of sipuleucel-T prolonged the median survival of men with mCRPC by 4.1 months compared to the placebo (25.8 vs. 21.7 months, respectively) [18].

\section{Bone-Targeting Agents}

Bone metastases occur in most of the patients with mCRPC, primarily affecting the structural integrity of bone and causing patient disability, pain, reduced quality of life (QOL), and death. Radium-223 was approved by the FDA in 2013, based on the data of the phase III ALSYMPCA (Alpharadin in Symptomatic Prostate Cancer Patients) trial. The phase II ALSYMPCA trial showed an OS gain of 2.8 months over placebo (14.0 vs. 11.2 months, respectively; $p=0.002$ ) in men with mCRPC (and symptomatic bone metastasis) [19]. The trial also demonstrated reduced pain and improved symptomatic skeletal events in patients with mCRPC without visceral disease [20]. Additionally, a retrospective cohort study showed that the concomitant use of other bone-modifying agents, such as denosumab or zoledronic acid, with other relatively new agents is a common clinical practice 
for the treatment of CRPC patients with bone metastases [21].

In a long-term placebo-controlled randomized clinical trial (RCT), treatment with $4 \mathrm{mg}$ zoledronic acid was associated with skeletal-related events (SREs) versus placebo in men with hormone refractory prostate cancer at 24 months (38 vs. 49\%; difference - $11.0 \%$, $95 \%$ confidence interval $[\mathrm{CI}]-20.2$ to $-1.3 \%$; $p=0.028)$. The median time to first SRE was 488 days compared to 321 days with placebo $(p=0.009)$. The ongoing risk of SREs was reduced by $36 \%$ with zoledronic acid compared to placebo (risk ratio $0.64,95 \%$ CI $0.485-0.845$; $p=0.002$ ) [22]. In a phase 3 RCT, denosumab (120 mg) was found to be better than zoledronic acid (4 mg) at preventing SREs (median time to first SRE 20.7 vs. 17.1 months, respectively; hazards ratio [HR] 0.82 , 95\% CI 0.71-0.95; $p=0.0008)$. However, hypocalcemia occurred more frequently in the denosumab group than in the zoledronic acid group [23].

\section{Trends in Sequencing Treatments for mCRPC}

To date, no clear recommendations are available for guiding the appropriate treatment sequence in mCRPC. Currently, the choice for further treatment following the development of castration resistance is unclear. Furthermore, cross-resistance is also commonly observed between abiraterone and enzalutamide when these drugs are used sequentially for the treatment of mCRPC. The Kyoto-Baltimore Collaboration report suggested that abiraterone as the first-line treatment before enzalutamide prolonged the PFS (HR 0.56; $p<0.001$ ), but not OS. This effect is relative to enzalutamide as firstline treatment before abiraterone in patients with chemotherapy-naïve castration-resistant prostate cancer [24]. However, OZM-054, a phase II, randomized trial compared the clinical benefit (defined as PSA decline $\geq 50 \%$ or stable disease for $\geq 12$ weeks) of cabazitaxel and the combination abiraterone/enzalutamide in patients with mCRPC expressing poor outcomes [25]. In the first-line treatment, a significantly higher number of patients benefited from receiving cabazitaxel over abiraterone/enzalutamide (90 vs. $70 \% ; p=0.02$ ). In terms of second-line therapy upon cross-over, there was no difference between treatment groups in PSA50 (50\% decline in PSA), measurable disease response, or stable disease at $>12$ weeks ( 75 vs. $85 \% ; p=0.483)$. In addition, the study did not demonstrate an OS benefit $(p=0.143)$ with upfront cabazitaxel over abiraterone/enzalutamide in these patients [25]. The PROREPAIR-B cohort study demonstrated significantly longer PFS among men with mCRPC who received abiraterone or enzalutamide upfront compared with those who received first-line docetaxel (10.8 vs. 8.3 months; $p<0.001$ ). However, no significant differences in the OS were observed with both treatment sequences [26]. Another retrospective study of treatment sequences in real-world practice among men with mCRPC showed no significant difference in OS with abiraterone first followed by enzalutamide, or the reverse sequence; abiraterone or enzalutamide first followed by docetaxel, or the reverse sequence; or docetaxel first followed by cabazitaxel [27]. In the CARD study, which included mCRPC patients progressing after docetaxel and abiraterone/enzalutamide, cabazitaxel significantly improved median imaging-based PFS compared to enzalutamide/ abiraterone (8.0 vs. 3.7 months) and OS (13.6 vs. 11.0 months; HR for death $0.64,95 \%$ CI $0.46-0.89 ; p=0.008)$. The median PFS was 4.4 months with cabazitaxel versus 2.7 months with abiraterone/enzalutamide (HR for progression or death 0.52 , 95\% CI $0.40-0.68$; $p<0.001)$ [28].

\section{Evolution of Precision Oncology in $\mathrm{mCRPC}$}

Precision medicine is an evolving field in medical oncology that has been used to determine the diagnostic subcategories of various diseases and patient prognosis and develop targeted and individualized treatment approaches [29]. Prostate cancer is one of the original cancers for which precision oncology has been adopted. The discovery of AR has paved way to the introduction of the concept of targeted treatment with LHRH agonists and novel ART therapies. Although these treatments are effective, some patients eventually develop resistance, 
resulting in progression to mCRPC $[11,12]$. However, recent advancements in precision oncology have shed light on several other pathways, apart from AR, which could be targeted for better outcomes in mCRPC patients, such as DNA damage repair (DDR), deficient mismatch repair (dMMR), and programmed cell death-1 (PD-1) receptor pathways.

\section{DNA Repair Defects and Precision Oncology in $\mathrm{MCRPC}$}

A family history of prostate cancer has been long recognized as a major risk factor (60\%) [30]. Patients with mCRPC can have genomic aberrations that interfere with the DDR pathway [31]. These include somatic (23\%) [32] and/ or germline $(11.8 \%)$ alterations in DDR genes, such as BRCA1 (germline 0.9\%, somatic 0.9\%), BRCA2 (germline $8.6 \%$, somatic $7.7 \%$ ), ataxiatelangiectasia mutated (ATM) (germline 2.3\%, somatic $4.5 \%$ ), and CHEK2 (germline $4.1 \%$, somatic $0.9 \%$ ), and also in other genes with direct and indirect roles in homologous recombination repair (HRR), such as BRIP1, BARD1, CDK12, CHEK1, FANCL, PALB2, PPP2R2A, RAD51B, RAD51C, RAD51D, or RAD54L [33, 34].

Germline BRCA1 and BRCA2 mutations in men are associated with a significant increase in aggressive prostate cancer risk. By the age of 65 years, $B R C A 1$ and $B R C A 2$ carriers are at 3.75and 8.6-fold increased risk of prostate cancer compared to non-carriers $[35,36]$. In addition, genetic mutations in HRR genes, BRCA1, $B R C A 2$, and $A T M$ have been found to be associated with an increased sensitivity to PARP inhibition [37]. Mateo et al. [38] conducted a phase II trial in which they studied the efficacy of a PARP inhibitor, olaparib, in mCRPC patients who progressed on standard therapy. Next-generation sequencing (NGS) identified deleterious mutations (somatic and germline) in DDR genes, including BRCA1/2, ATM, Fanconi's anemia genes (FANCA), and CHEK2 in 16 of 49 evaluated patients (33\%). Among these 16 patients, $14(88 \%)$ had a response to olaparib, including seven patients with loss of BRCA2 (4 with biallelic somatic loss and 3 with germline mutations) and four of five with an ATM mutation. This discovery that approximately half of these treatment-actionable genetic alterations lie in the germline DNA (and are therefore heritable) have had profound implications in the field of precision medical oncology in prostate cancer.

Results from the TOPARP study led to the design and conduct of the PROfound study, a prospective, randomized, open-label, phase III clinical trial with the aim to evaluate the efficacy and safety of olaparib versus enzalutamide or abiraterone in men with mCRPC who had failed prior treatment with a novel ART therapy (abiraterone or enzalutamide) and had a qualifying tumor mutation in $\geq 1$ of the 15 predefined genes (prospectively identified by the FoundationOne ${ }^{\circledR}$ CDx investigational NGS test) [36]. Those with alterations in BRCA1, BRCA2, and $A T M$ were included in cohort A $(n=245)$ based upon prevalence in the prostate population, while those with alterations in BRIP1, BARD1, CDK12, CHEK1, CHEK2, FANCL, PALB2, PPP2R2A, RAD51B, RAD51C, RAD51D, or RAD54L were included in cohort $\mathrm{B}(n=142)$. Patients in each cohort were randomized 2:1 to receive olaparib $300 \mathrm{mg}$ twice daily (BID) or the physician's choice of enzalutamide (160 mg/day) or abiraterone (1000 mg/day + prednisone $5 \mathrm{mg}$ BID) [39].

Olaparib resulted in a significant improvement in median radiographic PFS (rPFS; assessed by blinded independent central review [BICR]) compared to physicians' choice of treatment (enzalutamide/abiraterone) among patients in cohort A (7.4 vs. 3.55 months, respectively; HR $0.34 ; p<0.0001$ ) [39]. Olaparib also resulted in a significantly improved OS (median 18.5 vs. 15.11 months; HR 0.67, $p=0.0063$ ) and a significantly greater objective response rate $(33.3$ vs. $2.3 \%$ as assessed by BICR; odds ratio 20.86; $p<0.0001)$ and median time to pain progression (not reached vs. 9.92 months based on the Brief Pain Inventory [Short Form] worst pain [item 3] and opioid use; HR 0.44; $p=0.0192$ ). When cohort A and B were combined, improvement in rPFS shown in patients receiving olaparib was maintained (median 5.82 vs. 3.52 months; HR 0.49; $p<0.0001)$. Important toxicities included nausea, anemia elevation in liver enzymes, and gastrointestinal and hematological side effects. Additional toxicities 
observed in this study included a venous thromboembolism prevalence and potential induction of myelodysplastic syndrome/acute myeloid leukemia [39].

PROfound validated the concept of PARP sensitivity across multiple genes associated with HRR in mCRPC. It also highlighted the importance of genomic testing in prostate cancer and showed that identifying patients with DDR alterations in individual patients expands the treatment artillery available to include PARP inhibitors. However, the availability of more treatment options necessitate a better understanding of the optimal treatment sequence for individual patients.

Several other PARP inhibitors, such as rucaparib, niraparib, veliparib, and talazoparib, have been evaluated in phase II trials as monotherapy (Table 2). Similar to the study using olaparib, patients are being selected based upon the presence of DDR alterations, either from archival tumor specimens, cell-free DNA, or both. And again, like olaparib, each of these PARP inhibitors demonstrated impressive response rates in genomically selected patients. The most significant reported adverse events were hematologic (grade 3/4 anemia and thrombocytopenia), along with nonhematologic events, including gastrointestinal events, asthenia, and hypertension. [40] The details of ongoing phase II and III trials evaluating PARP inhibitors as monotherapy or in combination with other therapies as first-line or later-lines treatments in MCRPC are shown in Table 3.

In order to identify the DDR alterations that make patients eligible for treatment with PARP inhibitors, archival tumor tissues or cell-free tumor DNA are retrieved for NGS. However, a proportion of the DDR alterations detected are likely to be germline. While not addressed by any of the PARP inhibitor studies, the role of offering germline testing in such cases is important, given the implications for family members on cancer predisposition and the possibility to deploy risk-reduction strategies at an early stage [32, 33].

It is important for pathologists and clinicians to understand the role and effect of potential targeted therapies in the light of germline (inherited) and somatic (acquired) mutations that occur in prostate cancer.

While germline genetic testing helps identify inherited pathogenic mutations in genes associated with familial cancer risk, tumor-directed somatic testing may guide treatment decisionmaking. Germline genetic testing can be performed on lymphocyte DNA from blood or a combination of lymphocyte and buccal cells from saliva, obtained non-invasively; on the other hand, somatic testing is complex and requires prostate tumor material from biopsies, or in some cases, circulating tumor cells/DNA (ctDNA) in the blood. Additionally, outside the clinical trials in the real-world settings, obtaining sufficient and high-quality tumor tissue for complicated somatic analysis is not a trivial process in patients with mCRPC [41]. Using archived tissue samples may enable wider testing, but there are risks of missing the evolution of somatic mutations in the tumor tissue due to genetic instability [42]. As a result, repeat testing of tumor DNA is required during the disease course.

Although somatic testing may help identify potential germline mutations [43], it should never be used to substitute for germline testing, primarily because of the risk for false-positives and false-negatives owing to the variations in reporting between different commercially available tests. However, contemporary sampling of metastatic disease sites or cell-free ctDNA using liquid biopsy may be more informative and a novel way to identify genomic alterations and track patient's genomic landscape over time [44].

Despite extensive investigations, the identification of rare germline mutations in prostate cancer genes has been extremely challenging. Four major factors contributing to the challenges include: (1) the genetic heterogeneity of prostate cancer, (2) the high rate of sporadic disease, (3) large well-annotated patient populations needed to establish associations between germline pathogenic mutations and prostate cancer, and (4) the high cost of sequencing. 


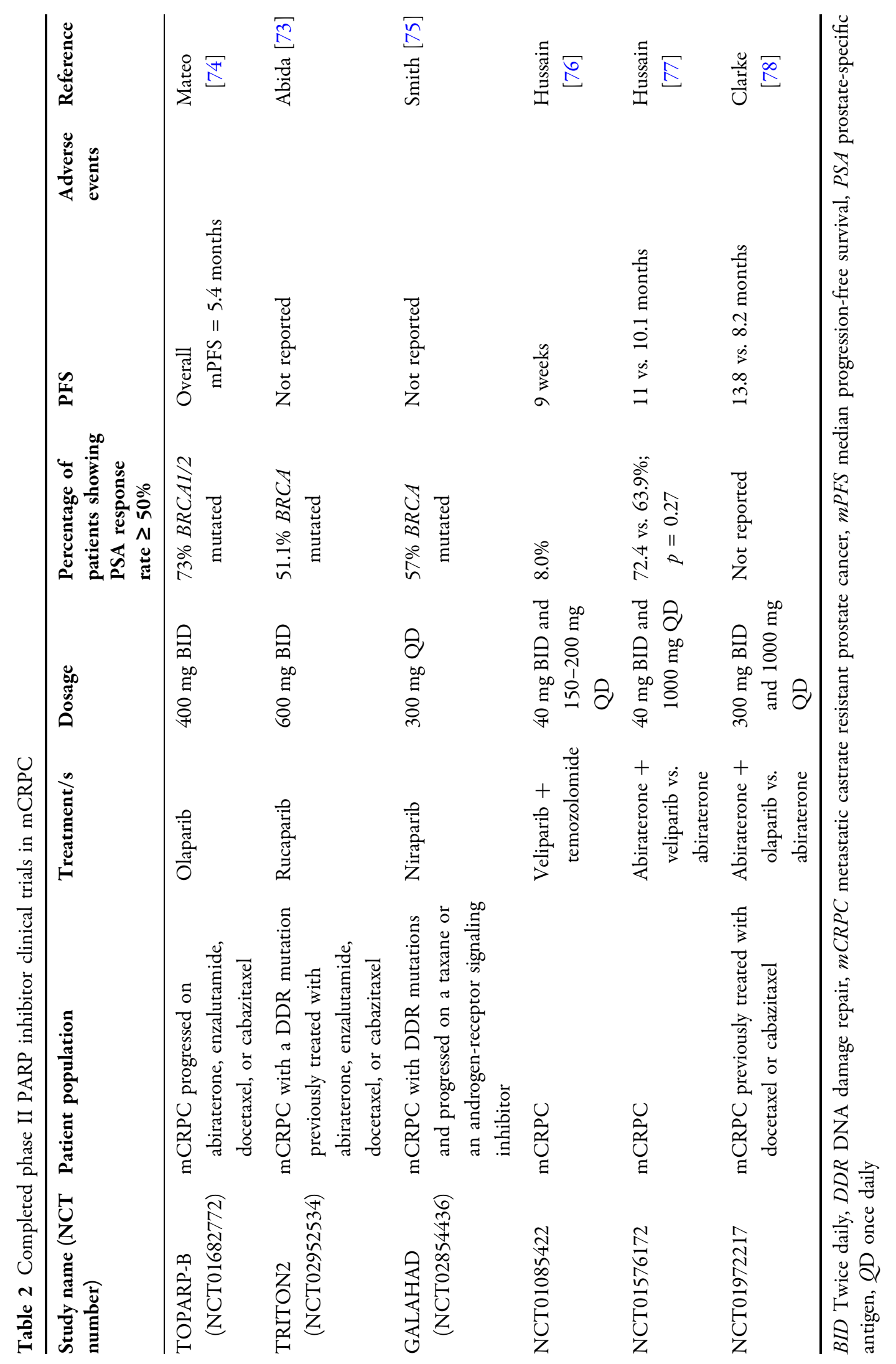


Table 3 Ongoing PARP inhibitor clinical trials in mCRPC

\begin{tabular}{|c|c|c|c|c|}
\hline $\begin{array}{l}\text { Study name (NCT } \\
\text { number) }\end{array}$ & Phase & Patient population & Treatment/s & $\begin{array}{l}\text { Primary } \\
\text { endpoint }\end{array}$ \\
\hline $\begin{array}{l}\text { TALAPRO-1 } \\
\text { (NCT03148795) } \\
{[79]}\end{array}$ & $\begin{array}{l}\text { Phase } \\
\text { II }\end{array}$ & $\begin{array}{l}\text { DDR-mutated mCRPC progressed } \\
\text { on a taxane or an androgen- } \\
\text { receptor signaling inhibitor }\end{array}$ & Talazoparib & ORR \\
\hline $\begin{array}{l}\text { ROAR } \\
\qquad(\text { NCT03533946) }\end{array}$ & $\begin{array}{l}\text { Phase } \\
\text { II }\end{array}$ & DDR-mutated mCRPC & Rucaparib & $\begin{array}{l}\text { PSA } \\
\text { decline } \geq 50 \% \\
\text { rate }\end{array}$ \\
\hline $\begin{array}{l}\text { TRITON } 3 \\
\text { (NCT02975934) }\end{array}$ & $\begin{array}{c}\text { Phase } \\
\text { III }\end{array}$ & $\begin{array}{l}\text { Germline or somatic } B R C A 1 \text {, } \\
B R C A 2 \text {, or } A T M \text { mutations and } \\
\text { mCRPC who previously } \\
\text { progressed on an androgen- } \\
\text { receptor signaling inhibitor and } \\
\text { who have not received } \\
\text { chemotherapy }\end{array}$ & $\begin{array}{l}\text { Rucaparib vs. abiraterone, } \\
\text { enzalutamide, or docetaxel }\end{array}$ & PFS \\
\hline $\begin{array}{l}\text { PROpel } \\
\qquad(\text { NCT03732820) }\end{array}$ & $\begin{array}{c}\text { Phase } \\
\text { III }\end{array}$ & $\begin{array}{l}\text { mCRPC who have not received } \\
\text { taxane chemotherapy or an } \\
\text { androgen-receptor signaling } \\
\text { inhibitor }\end{array}$ & $\begin{array}{l}\text { Abiraterone and olaparib vs. } \\
\text { abiraterone and placebo }\end{array}$ & PFS \\
\hline $\begin{array}{l}\text { BRCAaway } \\
\text { (NCT03012321) } \\
{[80]}\end{array}$ & $\begin{array}{l}\text { Phase } \\
\text { II }\end{array}$ & DDR-mutated mCRPC & $\begin{array}{l}\text { Abiraterone vs. olaparib, and } \\
\text { abiraterone vs. olaparib }\end{array}$ & PFS \\
\hline $\begin{array}{l}\text { TALAPRO-2 } \\
\text { (NCT03395197) } \\
{[81]}\end{array}$ & $\begin{array}{c}\text { Phase } \\
\text { III }\end{array}$ & $\begin{array}{l}\text { Asymptomatic or mildly } \\
\text { symptomatic mCRPC, without } \\
\text { brain metastases, never having } \\
\text { received taxane-chemotherapy or } \\
\text { an androgen-receptor signaling } \\
\text { inhibitor }\end{array}$ & $\begin{array}{l}\text { Enzalutamide }+ \text { talazoparib vs. } \\
\text { enzalutamide }+ \text { placebo } \\
\text { (prestratified based on DDR } \\
\text { mutation status) }\end{array}$ & PFS \\
\hline $\begin{array}{l}\text { MAGNITUDE } \\
(\text { NCT03748641) }\end{array}$ & $\begin{array}{c}\text { Phase } \\
\text { III }\end{array}$ & Treatment-naïve mCRPC & $\begin{array}{l}\text { Niraparib }+ \text { abiraterone vs. } \\
\text { abiraterone }+ \text { placebo }\end{array}$ & PFS \\
\hline $\begin{array}{l}\text { KEYLINK-010 } \\
\text { (NCT03834519) }\end{array}$ & $\begin{array}{c}\text { Phase } \\
\text { III }\end{array}$ & $\begin{array}{l}\text { mCRPC progressed on an androgen- } \\
\text { receptor signaling inhibitor }\end{array}$ & $\begin{array}{l}\text { Pembrolizumab }+ \text { olaparib vs. } \\
\text { enzalutamide or abiraterone }\end{array}$ & PFS and OS \\
\hline
\end{tabular}

DDR DNA damage repair, $m C R P C$ Metastatic castrate resistant prostate cancer, ORR Overall response rate, PARP:PFS Progression-free survival, PSA: prostate specific antigen

\section{RECOMMENDATIONS FOR ADOPTING PRECISION ONCOLOGY IN MCRPC}

The NCCN guidelines have the following recommendations for germline and somatic genetic testing in prostate cancer patients (Box 1 and Box 2) [16].

In addition to the NCCN guidelines, the evidence gathered from the PROfound study would propel the need for routine genetic testing to inform PARP inhibitor treatment in 
mCRPC patients. [39]. Germline and tumor testing findings may overlap. An individual with cancer who has an inherited BRCA mutation will also have the same mutation in his/her tumor. Therefore, germline versus somatic testing remains debatable, and depending on the cancer type, both tumor and germline testing may be used to help select treatment options. However, in most regions across the globe, genetic testing is expensive and, hence, considered to be optimal only in second- or thirdline settings after failure of first-line hormone therapy and/or chemotherapy. Nevertheless, if cost is not a constraint, somatic testing may be considered early after the diagnosis of prostate cancer. If mutations in BRCA1, BRCA2, ATM, $P A L B 2$, and CHEK2 genes are found, then such patients should be referred for germline testing, irrespective of family history of cancer.

There are several barriers to the widespread use of genetic testing in prostate cancer patients, including [45]:

1. Delayed or limited access to genetic counseling. The data from a workforce study indicated a shortage of genetic counselors engaged in direct patient care. The increasing demand for genetic counselors and the supply of such counselors to the workforce have been estimated to reach equilibrium only between 2024 and 2030 [46]. In this scenario, new strategies are needed to deliver effective genetic counseling. Patients with prostate cancer who are eligible for genetic testing may undergo counseling by trained healthcare providers in urology, radiation oncology, or medical oncology who are treating the patient. The ENGAGE study recently reported the results of an oncologist-led BRCA testing program in women with ovarian cancer, which demonstrated an efficient turnaround time of 4 weeks in the USA along with high levels of patient and physician satisfaction [47]. Remote video or telephone visits have also gained prominence as an effective means of increasing access to genetic counseling $[48,49]$.

2. Limited/no insurance coverage. Despite the new NCCN guidelines recommending germline genetic testing for all men with metastatic or high-risk, non-metastatic prostate cancer and somatic testing for patients with metastatic prostate cancer, reimbursement and coverage of genetic testing are not universal and vary among companies, primarily because of the lack of recognition of or difficulty in accreditation by public and/or private healthcare insurance bodies [50]; thus, coverage often depends on men having an additional family history. This has limited access to expensive genetic services (somatic testing in Colombia is much more expensive, ranging from US\$3000 to $\$ 4000$, than germline testing costing around US\$400) within the healthcare system [51] and has led to the utilization of NGS-based multigene panel testing [52].

3. Insufficient training and education materials for both clinicians and patients. There is a need to provide basic genomics training to all nongenetic healthcare professionals, including oncologists, surgeons, and primary care physicians, with the aim to provide better counseling to patients before testing and a more informed discussion of the results after testing [53, 54].

4. Patient barriers. Despite the evident benefits of genetic testing and counseling in terms of obtaining information on the cancer risk, not all eligible individuals choose to undergo testing due to a number of reasons, including non-priority, concerns about lack of insurance, low socioeconomic status, distance to clinics, time away from work and family, lack of patient/provider knowledge on the value of genetic counseling, concern of discrimination against them in case of positive genetic test result [55], fear and apprehension about the test procedures and results, and lack of encouragement 
from family [56, 57]. Studies have found that ethnic minority groups are underserved with respect to genetic services and underrepresented in research $[58,59]$. Low community awareness and understanding of familial cancer risk, socio-cultural differences in beliefs, and the stigma about cancer or inherited risk of cancer may further contribute to disparities in referral [60]. In addition, it is observed that members of families having an identified $B R C A$ mutation are more likely to choose to undergo testing when they are older ( $\geq 40$ years), are married, and have higher level of cohesiveness in their families [61].

5. Additional barriers to genetic testing and counseling include time and space constraints in busy clinics, obtaining good quality tissue samples after repeated biopsies, and possible psychological burden on patients and families imposed by genetic testing.

In addition, there are specific challenges that stand against the implementation of precision medicine in patients with prostate cancer in emerging countries.

1. Financial. It is understood that the cost of NGS continues to be prohibitive in emerging countries, especially in the setting of a large-scale implementation plan by the government. In some countries, this will lead to greater disparity in outcomes, as only patients with high-end medical insurance plans will benefit from a precision medicine approach [62, 63].

2. Ability of both clinicians and molecular pathologists to be/keep up to date with the rapidly changing treatment landscape. Interpreting molecular results will require the expertise of molecular pathologists and geneticists [64]. While molecular tumor boards [65] are becoming more established in the Western world, they remain an uncommon phenomenon in emerging countries. Thus, educating both clinicians and molecular pathologists is essential to ensure adoption of precision oncology.

Box 1: NCCN Guideline Recommendations for Germline Genetic Testing in Prostate Cancer

Germline mutations should be tested in all newly diagnosed men with NCCN high-risk, very high-risk, regional, or metastatic prostate cancer, regardless of family history and also for every patient with highrisk, localized non-metastatic prostate cancer.

Germline testing is suggested for the following genes: BRCA1, BRCA2, ATM, PALB2, CHEK2, MLH1, $M S H 2, M S H 6$, and $P M S 2$, using NGS panel testing.

Family history of high-risk germline mutations (e.g., $B R C A 1 / 2$, Lynch mutation).

A positive family history indicative of germline mutations includes a brother, father, or multiple family members having been diagnosed with prostate cancer at age $<60$ years, $\geq 3$ cancers on the same side of family, especially diagnoses at age $\leq 50$ years of bile duct, breast, colorectal, endometrial, gastric, kidney, melanoma, ovarian, pancreatic, prostate (but not clinically localized Grade Group 1), small bowel, or urothelial cancer.

Ashkenazi Jewish ancestry is also a familial risk factor. Anyone who has intraductal histology should also undergo genetic testing. 
Box 2: NCCN Guideline Recommendations for Somatic Testing in Prostate Cancer

Recommend evaluating tumor for alterations in homologous recombination DNA repair genes, such as BRCA1, BRCA2, ATM, PALB2, FANCA, RADS1D, CHEK2, and CDK12, in patients with metastatic prostate cancer. If mutations in BRCA1, BRCA2, ATM, PALB2, and CHEK2 are found and/ or there is a strong family history of cancer, refer to genetic counseling for confirmatory germline testing.

Patients should be informed that somatic tumor sequencing has the potential to uncover germline findings. However, virtually no somatic NGS test is designed or validated for germline assessment. If a germline mutation is suspected, the patient should be recommended for follow-up with genetic counseling and dedicated germline testing.

Tumor testing for microsatellite instability (MSI) or $\mathrm{dMMR}$ can be considered in patients with regional or metastatic prostate cancer.

Men with lymph node metastases or distant metastases should also undergo tumor somatic testing.

\section{GAPS IN KNOWLEDGE OF PRECI- SION ONCOLOGY}

It is now well-established through precision medicine that BRCA2 gene deletions and ATM point mutations are the most common mutations in HRR genes in MCRPC, accounting for $20 \%$ of all mutations, and that PARP inhibitors (e.g., olaparib) may be a promising treatment strategy for mCRPC patients harboring HRR mutations [31]. With newer strategies becoming availabile, such as individual genomic and proteomic profiling targeting specific cancer pathways, gene editing technologies, and liquid tumor profiling, and with an increasing number of prostate cancer patients being subjected to exome and whole-genome sequencing, it is now easier to characterize even the rarer mutations in HRR genes in patients with mCRPC. These include BRCA1, which is mutated in $<1 \%$ of CRPC patients, PALB2, CDK12, and Fanconi anemia complex members (e.g., FANCA, RAD51D, RAD51C, and CHEK2) [33].

The most efficient way to improve our understanding of the rarer genes and to optimize treatment selection and sequencing patterns in mCRPC is through access to real-world data (RWD) on patterns of diagnosis and care and real-world evidence (RWE) on treatment outcomes facilitated by clinician-led data registries in oncology. RWD would help produce robust clinical evidence that would further help clinicians and researchers answer simple, pragmatic questions, such as treatment duration and strategies, or combinations of these, at a far lower cost than conventional randomized trials. Further, RWD registries are an important part of clinical research and may be combined with RCTs to create registry-based RCTs or registry trials. Several prospective prostate cancer registries exist to date, such as the University of California, San Francisco (UCSF) Cancer of the Prostate Strategic Urologic Research Endeavor (CaPSURE; USA); the Michigan Urological Survey Improvement Collaborative (MUSIC; USA); and the South Australian Prostate Cancer Clinical Outcome Collaborative (SA-PCCOC; Australia). These registries are able to collect detailed information on disease recurrence, clinical diagnosis and progression, treatment, follow-up, disease-specific mortality, and functional outcomes in patients after treatments [62]. The Victoria Prostate Cancer Registry (Australia) has been developed with the aim of monitoring the quality of care provided to men diagnosed with prostate cancer. The Korean Prostate Cancer Database (K-CaP) collects data in order to analyze clinical and pathologic prostate cancer outcomes with the ultimate aim to improve patient care [66].

Knowledge on the clinical diagnostic and treatment patterns in mCRPC is largely fragmented across Asia. To address these knowledge gaps, a prospective, longitudinal, prostate cancer disease registry, called the United in Fight against Prostate Cancer (UFO), has been developed with the aim of providing a comprehensive picture of the diagnosis, prognosis, treatment outcome, population characteristics, health-related QOL, and comorbidities in patients with prostate cancer in real-world 
clinical practice in eight countries across Asia, including China, India, Japan, Malaysia, Singapore, South Korea, Taiwan, and Thailand [67, 68]. PROXIMA (Treatment Patterns in Patients with Metastatic Castration-Resistant Prostate Cancer Previously Treated with Docetaxel-Based Chemotherapy) is a large, global, noninterventional, prospective registry study evaluating real-world treatment patterns of patients with MCRPC who experienced disease progression during or after docetaxel therapy. The data obtained from such registries may be used to devise optimal therapy sequences and inform treatment decisions [69].

In addition to generating RWE, it is also important to harmonize the assays and the gene panels currently available for prostate cancer testing. Additionally, only a small fraction of tumors $(2-3 \%)$ in mCRPC patients show MMR defects [34] and therefore benefit from anti-PD1/programmed death-ligand 1 (PD-L1) therapy. However, hypermutated MMR-deficient prostate cancers may show strong response to checkpoint inhibition [70]. Biomarker-driven ctDNA analysis may provide promising results in this field by identifying the mCRPC cases with MMR deficiency [71].

\section{CONCLUSIONS}

Metastatic castration-resistant prostate cancer is a life-threatening disease and represents an area of critical unmet medical need. Prostate cancer is one of the initial cancers demonstrating promising results through the precision oncology-directed treatment approach with novel ART therapies. Currently, HRR has been identified as an additional driver that is actionable through olaparib and other PARP inhibitors. In this era of an evolving therapeutic landscape of mCRPC, head-to-head comparisons of drugs and specific combinations and treatment sequences have become more significant. Further development is needed in providing accessibility to prompt genetic testing in mCRPC patients and their family members at high risk of developing the disease. With rapid advancements in this field, a close collaboration between oncologists, urologists, clinical geneticists and counselors, researchers, and, indeed, patients themselves is required to ensure the best clinical management practices to benefit patients with mCRPC. By complementing the safety and efficacy data obtained from optimized patient population in RCTs, RWD may provide valuable information and support, improve, and potentially accelerate the delivery of safe and cost-effective therapeutic interventions to patients. A detailed review of the evidence-based answers to key clinical questions along with expert views for optimizing the treatment of mCRPC has been provided in the current article.

\section{ACKNOWLEDGEMENTS}

Funding. This study and the Journal's Rapid Service Fee was funded by AstraZeneca.

Medical Writing/Editorial Assistance. We would like to thank BioQuest solutions for their editorial assistance.

Authorship. All named authors meet the International Committee of Medical Journal Editors (ICMJE) criteria for authorship for this article, take responsibility for the integrity of the work as a whole, and have given their approval for this version to be published.

Authorship Contributions. All authors have contributed equally towards design, conception, review and finalization of manuscript.

Disclosures. Shouki Bazarbashi has participated in speaker bureaus and advisory boards; and received conference support/research support from Lilly, Pfizer, Roche, Servier, Merck Serono, Janssen, Merck-Sharp and Dohme, Astellas, Bristol-Myers Squibb, AstraZeneca, Amgen, Kyowa Kirin, and Bayer. Ramanujam Anugonda Singarachari has been part of Advisory Boards for AstraZeneca and received consulting fees from AstraZeneca. Diogo A. Bastos has received research funding from Janssen, Astellas, and Bayer; honoraria from Janssen, Astellas, Bayer, AztraZeneca, BMS, MSD, and 
Roche; and has been consultant/advisor for Janssen, Astellas, Bayer, AztraZeneca, BMS, and MSD.All other authors confirm they do not have any conflict of interests.

Compliance with Ethics Guidelines. This article is based on previously conducted studies and does not contain any studies with human participants or animals performed by any of the authors.

Data availability. Data sharing is not applicable to this article as no datasets were generated or analyzed during the current study.

Open Access. This article is licensed under a Creative Commons Attribution-NonCommercial 4.0 International License, which permits any non-commercial use, sharing, adaptation, distribution and reproduction in any medium or format, as long as you give appropriate credit to the original author(s) and the source, provide a link to the Creative Commons licence, and indicate if changes were made. The images or other third party material in this article are included in the article's Creative Commons licence, unless indicated otherwise in a credit line to the material. If material is not included in the article's Creative Commons licence and your intended use is not permitted by statutory regulation or exceeds the permitted use, you will need to obtain permission directly from the copyright holder. To view a copy of this licence, visit http://creativecommons.org/licenses/bync/4.0/.

\section{REFERENCES}

1. Sung H, Ferlay J, Siegel RL, et al. Global cancer statistics 2020: GLOBOCAN estimates of incidence and mortality worldwide for 36 cancers in 185 countries. CA Cancer J Clin. 2021;71(3):209-49.

2. Antonarakis ES, Feng Z, Trock BJ, et al. The natural history of metastatic progression in men with prostate-specific antigen recurrence after radical prostatectomy: long-term follow-up. BJU Int. 2012;109:32-9.
3. Crawford ED, Petrylak D, Sartor O. Navigating the evolving therapeutic landscape in advanced prostate cancer. Urol Oncol. 2017;35:S1-13.

4. Tannock IF, Osoba D, Stockler MR, et al. Chemotherapy with mitoxantrone plus prednisone or prednisone alone for symptomatic hormone-resistant prostate cancer: a Canadian randomized trial with palliative end points. J Clin Oncol. 1996;14: 1756-810.

5. Kantoff PW, Halabi S, Conaway M, et al. Hydrocortisone with or without mitoxantrone in men with hormone-refractory prostate cancer: results of the cancer and leukemia group B 9182 study. J Clin Oncol. 1999;17:2506-13.

6. Tannock IF, Wit RD, Berry WR, et al. Docetaxel plus prednisone or mitoxantrone plus prednisone for advanced prostate cancer. N Engl J Med. 2004;351: 1502-12.

7. Petrylak DP, Tangen CM, Hussain MHA, et al. Docetaxel and estramustine compared with mitoxantrone and prednisone for advanced refractory prostate cancer. N Engl J Med. 2004;351:1513-20.

8. De Bono JS, Oudard S, Ozguroglu M, et al. Prednisone plus cabazitaxel or mitoxantrone for metastatic castration-resistant prostate cancer progressing after docetaxel treatment: a randomised open-label trial. Lancet. 2010;376: 1147-54.

9. Eisermann K, Fraizer G. The androgen receptor and VEGF: mechanisms of androgen-regulated angiogenesis in prostate cancer. Cancers (Basel). 2017;9: E32.

10. Caubet JF, Tosteson TD, Dong EW, et al. Maximum androgen blockade in advanced prostate cancer: a meta-analysis of published randomized controlled trials using nonsteroidal antiandrogens. Urology. 1997;49:71-8.

11. De Bono JS, Logothetis CJ, Molina A, et al. Abiraterone and increased survival in metastatic prostate cancer. N Engl J Med. 2011;364:1995-2005.

12. Ryan CJ, Smith MR, de Bono JS, et al. Abiraterone in metastatic prostate cancer without previous chemotherapy. N Engl J Med. 2013;368:138-48.

13. Ryan CJ, Smith MR, Fizazi K, et al. Abiraterone acetate plus prednisone versus placebo plus prednisone in chemotherapy-naive men with metastatic castration-resistant prostate cancer (COU-AA-302): final overall survival analysis of a randomised, double-blind, placebo-controlled phase 3 study. Lancet Oncol. 2015;16:152-60. 
14. Beer TM, Armstrong AJ, Rathkopf DE, et al. Enzalutamide in metastatic prostate cancer before chemotherapy. N Engl J Med. 2014;371:424-33.

15. Scher HI, Fizazi K, Saad F, et al. Increased survival with enzalutamide in prostate cancer after chemotherapy. N Engl J Med. 2012;367:1187-97.

16. Mohler JL, Antonarakis ES, Armstrong AJ, et al. Prostate cancer, version 2.2019, NCCN Clinical Practice Guidelines in Oncology. J Natl Compr Canc Netw. 2019;17(5):479-505.

17. Rathkopf DE, Antonarakis ES, Shore ND, et al. Safety and antitumor activity of apalutamide (ARN509) in metastatic castration-resistant prostate cancer with and without prior abiraterone acetate and prednisone. Clin Cancer Res. 2017;23:3544e51.

18. Kantoff P, Paszulewicz A, Holko P, Pilc A. Sipuleucel-T immunotherapy for castration-resistant prostate cancer. N Engl J Med. 2010;363:411-22.

19. Parker C, Nilsson S, Heinrich D, et al. Alpha emitter radium-223 and survival in metastatic prostate cancer. N Engl J Med. 2013;369:213-23.

20. Sartor O, Coleman R, Nilsson S, et al. Effect of radium-223 dichloride on symptomatic skeletal events in patients with castration-resistant prostate cancer and bone metastases: results from a phase 3, double-blind, randomised trial. Lancet Oncol. 2014;15:738-46.

21. Liede A, Wade S, Lethan J, et al. An observational study of concomitant use of emerging therapies and denosumab or zoledronic acid in prostate cancer. Clin Ther. 2018;40:536-49e3.

22. Saad F, Gleason DM, Murray R, et al. Long-term efficacy of zoledronic acid for the prevention of skeletal complications in patients with metastatic hormone-refractory prostate cancer. J Natl Cancer Inst. 2004;96(11):879.

23. Fizazi K, Carducci M, Smith $M$, et al. Denosumab versus zoledronic acid for treatment of bone metastases in men with castration-resistant prostate cancer: a randomised, double-blind study. Lancet. 2011;377(9768):813-22.

24. Terada N, Maughan BL, Akamatsu S, et al. Exploring the optimal sequence of abiraterone and enzalutamide in patients with chemotherapy-naïve castration-resistant prostate cancer: the KyotoBaltimore collaboration. Int J Urol. 2017;24:441-8.

25. Chi KN. ESMO 2018: Cabazitaxel vs abiraterone or enzalutamide in poor prognosis metastatic castration-resistant prostate cancer patients. https:// www.urotoday.com/conference-highlights/esmo2018/esmo-2018-prostate-cancer/107719-esmo- 2018-cabazitaxel-vs-abiraterone-or-enzalutamidein-poor-prognosis-metastatic-castration-resistantprostate-cancer.html. Accessed 5 June 2021.

26. Cattrini C, Laorden NR, Castro E, et al. Impact of treatment sequence in patients (pts) with metastatic castration-resistant prostate cancer (mCRPC): data from the prospective PROREPAIR-B study. Ann Oncol. 2019;30:v325-55.

27. Okita K, Hatakeyama S, Narita S, et al. The effect of treatment sequence on overall survival for men with metastatic castration-resistant prostate cancer: a multicenter retrospective study. Clin Genitourin Cancer. 2020;18:e103-11.

28. de Wit R, de Bono J, Sternberg CN, et al. Cabazitaxel versus abiraterone or enzalutamide in metastatic prostate cancer. N Engl J Med. 2019;381(26): 2506-18.

29. McCrea EM, Lee DK, Sissung TM, Figg WD. Precision medicine applications in prostate cancer. Ther Adv Med Oncol. 2018;10:1758835918776920.

30. Hjelmborg JB, Scheike T, Holst K, et al. The heritability of prostate cancer in the Nordic Twin study of cancer. Cancer Epidemiol Biomarkers Prev. 2014;23:2303-10.

31. Beltran H, Yelensky R, Frampton GM, et al. Targeted next-generation sequencing of advanced prostate cancer identifies potential therapeutic targets and disease heterogeneity. Eur Urol. 2013;63: 920-6.

32. Robinson D, Van Allen EM, Yi-Mi Wu, et al. Integrative clinical genomics of advanced prostate cancer. Cell. 2015;161:1215-28.

33. Pritchard CC, Mateo J, Walsh MF, et al. Inherited DNA-repair gene mutations in men with metastatic prostate cancer. N Engl J Med. 2016;375:443-53.

34. Abida W, Armenia J, Gopalan A, et al. Prospective genomic profiling of prostate cancer across disease states reveals germline and somatic alterations that may affect clinical decision making. JCO Precis Oncol. 2017;1:1-16.

35. Leongamornlert D, Mahmud N, Tymrakiewicz M, et al. Germline BRCA1 mutations increase prostate cancer risk. Br J Cancer. 2012;106:1697-701.

36. Kote-Jarai Z, Leongamornlert D, Saunders E, et al. $B R C A 2$ is a moderate penetrance gene contributing to young-onset prostate cancer: implications for genetic testing in prostate cancer patients. $\mathrm{Br} \mathrm{J}$ Cancer. 2011;105:1230-4.

37. Stover EH, Konstantinopoulos PA, Matulonis UA, et al. Biomarkers of response and resistance to DNA 
repair targeted therapies. Clin Cancer Res. 2016;22: 5651-60.

38. Mateo J, Carreira S, Sandhu S, et al. DNA-Repair defects and olaparib in metastatic prostate cancer. N Engl J Med. 2015;373:1697-708.

39. Hussain M, Mateo J, Fizazi K, et al. PROfound: phase 3 study of olaparib versus enzalutamide or abiraterone for metastatic castration-resistant prostate cancer (mCRPC) with homologous recombination repair (HRR) gene alterations. Ann Oncol. 2019;30: v851-934.

40. Nizialek E, Antonarakis ES. PARP inhibitors in metastatic prostate cancer: evidence to date. Cancer Manag Res. 2020;12:8105-14.

41. Jimenez RE, Atwell TD, Sicotte H, et al. A prospective correlation of tissue histopathology with nucleic acid yield in metastatic castration-resistant prostate cancer biopsy specimens. Mayo Clin Proc Innov Qual Outcomes. 2019;3:14-22.

42. Cheng HH, Sokolova AO, Schaeffer EM, Small EJ, Higano CS. Germline and somatic mutations in prostate cancer for the clinician. J Natl Compr Canc Netw. 2019;17:515-21.

43. Cheng HH, Klemfuss N, Montgomery B, et al. A pilot study of clinical targeted next generation sequencing for prostate cancer: consequences for treatment and genetic counseling. Prostate. 2016;76:1303-11.

44. Romanel A, Tandefelt DG, Conteduca V, et al. Plasma AR and abiraterone-resistant prostate cancer. Sci Transl Med. 2015;7:312re10.

45. Paller CJ, Antonarakis ES, Beer TM, et al. Germline genetic testing in advanced prostate cancer; practices and barriers: survey results from the germline genetics working group of the Prostate Cancer Clinical Trials Consortium. Clin Genitourin Cancer. 2019;17:275-82.e1.

46. Hoskovec JM, Benett RL, Carey ME, et al. Projecting the supply and demand for certified genetic counselors: a workforce study. J Genet Couns. 2017;27: 16-20.

47. Colombo N, Huang G, Scambia G, et al. Evaluation of a streamlined oncologist-led BRCA mutation testing and counseling model for patients with ovarian cancer. J Clin Oncol. 2018;36:1300-7.

48. Cohen SA, Marvin ML, Riley BD, et al. Identification of genetic counseling service delivery models in practice: a report from the NSGC service delivery model task force. J Genet Couns. 2013;22:411-21.
49. Kinney AY, Butler KM, Schwartz MD, et al. Expanding access to BRCA1/2 genetic counseling with telephone delivery: a cluster randomized trial. J Natl Cancer Inst. 2014;106:dju328.

50. Doyle N, Cirino A, Trivedi A, Flynn M. Exploring barriers to payer utilization of genetic counselors. J Genet Couns. 2015;24:122-33.

51. Leonhard JR, Munson PJ, Flanagan JD, et al. Analysis of reimbursement of genetic counseling services at a single institution in a state requiring licensure. J Genet Couns. 2017;26:852-8.

52. Clain E, Trosman JR, Douglas MP, Weldon CB, Phillips KA. Availability and payer coverage of $B R C A 1 / 2$ tests and gene panels. Nat Biotechnol. 2015;33:900-2.

53. Talwar D, Tung-Sung T, Foster M, Xu L, Lai-shin C. Genetics/genomics education for nongenetic health professionals: a systematic literature review. Genet Med. 2017;19:725-32.

54. Vadaparampil ST, Sherr CL, Cragun D, Malo TL, Pal T. Pretest genetic counseling services for hereditary breast and ovarian cancer delivered by non-genetics professionals in the State of Florida. Clin Genet. 2015;87(5):473-7.

55. Allain DC, Friedman S, Senter L, Nekhlyudov L. Consumer awareness and attitudes about insurance discrimination post enactment of the Genetic Information Non-discrimination Act. Fam Cancer. 2012;11:637-44.

56. Rolnick S, Rahm AK, Jackson JM, et al. Barriers in identification and referral to genetic counseling for familial cancer risk: the perspective of genetic service providers. J Genet Couns. 2011;20:314-22.

57. Schlich-Bakker KJ, Kroode HFJT, Wárlám-Rodenhuis CC, Bout JVD, Ausems MGEM. Barriers to participating in genetic counselling and $B R C A$ testing during primary treatment for breast cancer. Genet Med. 2007;9:766-77.

58. Wonderling D, Hopwood P, Cull A. A descriptive study of UK cancer genetics services: an emerging clinical response to the new genetics. Br J Cancer. 2001;85:166-70.

59. Armstrong K, Weber B, Stopfer G, et al. Early use of clinical BRCA1/2 testing: associations with race and breast cancer risk. Am J Med Genet. 2003;117A: 154-60.

60. Allford A, Qureshi N, Barwell J, Lewis C, Kai J. What hinders minority ethnic access to cancer genetics services and what may help? Eur J Hum Genet. 2014;22:866-74. 
61. Biesecker BB, Ishibe N, Hadley DW, et al. Psychosocial factors predicting $B R C A 1 / B R C A 2$ testing decisions in members of hereditary breast and ovarian cancer families. Am J Med Genet. 2000;93: 257-63.

62. Abu-Elmagd M, Assidi M, Schulten HJ, et al. Individualized medicine enabled by genomics in Saudi Arabia. BMC Med Genomics. 2015;8:S3.

63. AlHarthi FS, Qari A, Edress A, Abedalthagafi M. Familial/inherited cancer syndrome: a focus on the highly consanguineous Arab population. NPJ Genom Med. 2020;5:3.

64. Nesline MK, DePietro P, Dy GK, et al. Oncologist uptake of comprehensive genomic profile guided targeted therapy. Oncotarget. 2019;10:4616-29.

65. van der Velden DL, van Herpen CML, van Laarhoven HWM, et al. Molecular Tumor Boards: current practice and future needs. Ann Oncol. 2017;28: 3070-5.

66. Gandaglia G, Bray F, Cooperberg MR, et al. Prostate cancer registries: current status and future directions. Eur Urol. 2016;69:998-1012.

67. Liu Y, Uemura H, Dingwei Ye, et al. Prostate cancer in Asia: design of a patient registry to inform realworld treatments, outcomes, and quality of life. Prostate Int. 2019;7:108-13.

68. Uemura $\mathrm{H}, \mathrm{D}$ Ye, Kanesvaran $\mathrm{R}$, et al. United in Fight against prostate cancer registry (UFO): first results from a large, multi-center, prospective, longitudinal cohort study in Asia. Ann Oncol. 2018;29: vii271-302.

69. Akaza H, Procopio G, Pripatnanont C, et al. Metastatic castration-resistant prostate cancer previously treated with docetaxel-based chemotherapy: treatment patterns from the PROXIMA Prospective Registry. J Glob Oncol. 2018;4:1-12.

70. Zehir A, Benayed R, Shah RH, et al. Mutational landscape of metastatic cancer revealed from prospective clinical sequencing of 10,000 patients. Nat Med. 2017;23:703-13.

71. Annala M, Vandekerkhove G, Khalaf D, et al. Circulating tumor DNA genomics correlate with resistance to abiraterone and enzalutamide in prostate cancer. Cancer Discov. 2018;8:444-57.

72. Antonarakis ES, Piulats JM, Gross-Goupil M, et al. Pembrolizumab for treatment-refractory metastatic castration-resistant prostate cancer: multicohort, open-label phase II KEYNOTE-199 study. J Clin Oncol. 2020;38(5):395-405.
73. Abida W, Cheng ML, Armenia J, et al. Microsatellite instability in prostate cancer and response to immune checkpoint blockade. J Clin Oncol. 2018;36(15):5020.

74. Mateo J, Porta N, McGovern UB, et al. TOPARP-B: A phase II randomized trial of the poly(ADP)-ribose polymerase (PARP) inhibitor olaparib for metastatic castration resistant prostate cancers (mCRPC) with DNA damage repair (DDR) alterations. J Clin Oncol. 2019;37(15):5005-105.

75. Smith MR, Sandhu SK, Kelly WK, et al. Phase II study of niraparib in patients with metastatic castration-resistant prostate cancer (mCRPC) and biallelic DNA-repair gene defects (DRD): Preliminary results of GALAHAD. J Clin Oncol. 2019;37(7): 202.

76. Hussain M, Carducci M, Slovin S, et al. Targeting DNA repair with combination veliparib (ABT-888) and temozolomide in patients with metastatic castration-resistant prostate cancer. Invest New Drugs. 2014;32(5):904-12.

77. Hussain M, Daignault- Newton S, Teardowski PW, et al. Targeting androgen receptor and DNA repair in metastatic castration-resistant prostate cancer: results from NCI 9012. J Clin Oncol. 2018;36(10): 991-9.

78. Clarke N, Wiechno P, Alekseev B, et al. Olaparib combined with abiraterone in patients with metastatic castration-resistant prostate cancer: a randomized, double-blind, placebo-controlled, phase 2 trial. Lancet Oncol. 2018;19(7):975-86.

79. De Bono J S, Higano C S, Fred S, et al. TALAPRO-1: an open-label, response rate phase II study of talazoparib (TALA) in men with DNA damage repair (DDR) defects and metastatic castration-resistant prostate cancer (mCRPC) who previously received taxane-based chemotherapy (CT) and progressed on greater than or equal to one novel hormonal therapy (NHT). J Clin Oncol. 2019;37(7):TPS342.

80. Reichert Z, Carneiro B A, Daignault- Newton S, et al. A randomized phase II trial of abiraterone, olaparib or abiraterone + olaparib in patients with metastatic castration-resistant prostate cancer with DNA repair defects. J Clin Oncol. 2017;35(15):TPS5086.

81. Agarwal N, Shore N D, Dunshee C, et al. TALAPRO2: A two-part, placebo-controlled phase III study of talazoparib (TALA) with enzalutamide (ENZA) in metastatic castration-resistant prostate cancer (mCRPC). J Clin Oncol. 2019;37(7):TPS337. 